\title{
INTERPRETAÇÃO DA LEI PENAL
}

\author{
LUIZ ALBERTO MACHADO, \\ Professor de Direito Penal na Faculdade \\ de Direito da Universidade Federal do Paraná
}

\section{EVOLUÇÃO HISTORICA}

1. A antiguidade clássica não conheceu, por seu direito eminentemente prático, problemas de interpretação da lei. As penas, em espécie reduzida, tinham aplicação automática pelo reconhecimento da infração. Tão só no tocante aos crimes extra ordinem, no período Imperial, os juízes obtiveram maior liberdade de aplicar as sanções ad exemplum legis.

No direito intermédio, porém, a liberdade concedida aos magistrados - decorrência do poder político absoluto - era de tal ordem, na interpretação, que se pode afirmar, sem exagero, que acumulavam na prática as funções de legisladores. $O$ arbítrio judicial desmedido começava no fato das leis serem escritas em latim, sendo conseqüentemente, pouco ou nada conhecidas do povo, máxime se se considerar o pequeno número de alfabetizados. Acresça-se a isso a ampla liberdade de aplicação analógica, bem como a permissividade de retroação da lei, ainda que em prejuízo.

A reação dos pensadores, principalmente dos enciclopedistas, ao absolutismo político e a elaboração da teoria do contrato social, de ROUSSEAU, bem assim o alevantamento do jusnaturalismo, desaguou inclusive no problema da interpretação da lei penal. Isso porque a magistratura se constituía num dos sustentáculos do poder político absolutista.

Inspirado na obra de ROUSSEAU e empolgado com as proposições de MONTESQUIEU, ${ }^{1} \circ$ italiano CESARE BONESANA, de origem nobre (Marquês de Beccaria), escreveu o livro "Dei Delitti e delle

1. Espírito das Lois. 
Pene", no qual contesta frontalmente o direito do magistrado de interpretar a lei, chegando a afirmar textualmente que "não há nada mais perigoso do que o axioma comum de que é necessário consultar - espírito da lei ${ }^{\prime 2}{ }^{2}$

Esse movimento pendular muito explicável, para usar-se uma expressão de FRAGOSO, levou o problema ao extremo oposto. O código bávaro de 1913, da lavra de FEUERBACH, expressamente proibia a interpretação. O código criminal de 1830 , na aplicação das penas, adotava um sistema matemático: se, no cometimento do crime, só houvessem atenuantes, a pena seria a mínima; se houvesse concurso de atenuantes e agravantes, a pena seria o resultado da soma do grau máximo com o mínimo dividido por dois; e se só houvessem agravantes, a pena seria no grau máximo. Esse sistema, com a inclusão dos graus sub-máximo e sub-médio, prevaleceu no código penal republicano de 1890 .

Todo esse temor de interpretação da lei pelo magistrado levou FILANGIERI e ROMAGNOSI a proporem a criação de um Conselho de Censores, encarregado de interpretar a lei penal e ditar a jurisprudência obrigatória. Dele, disse CARRARA que deveria ser um Conselho de Legisladores, não de Censores, caso possível ditar-se a lei tão claramente.

Modernamente se admite a necessidade de interpretação em conseqüência da natural falha dos textos e da mutação sociológica. Neste particular há que se aduzir que a lei penal, fruto da consciência coletiva de que falava DEL VECCHIO (fonte de produção remota), é sempre historicamente atrasada. Vem regular necessidades de há muito emergentes. Caso se não admitisse a sua atualização social, deveria ser promulgada e ab-rogada. Sirva de exemplo o conceito de mulher honesta; sensivelmente diferente da época da promulgação do código (1940) e de hoje.

\section{CONCEITO}

2. MAURACH define a interpretação como o processo pelo qual se enchem de valor os preceitos jurídico-penais. ${ }^{3}$

Em verdade a interpretação só deve ser feita quando não se apreende, de imediato, de um texto obscuro, o seu sentido e a sua finalidade. Vale o brocardo in claris non fit interpretatio.

2. Dos Delitos e das Penas, ed. Hemus, p. 17

3. Trafado de Derecho Penal, v. 1, p. 105. 


\section{TEORIAS}

3. Duas correntes disputam a hegemonia do processo interpretativo: a subjetivista e a histórico-objetivista ou atualista. ${ }^{4}$

A teoria subjetivista busca, através da utilização tão só do elemento histórico, a vontade do legislador (voluntas iegislatoris). Ora, nada mais fugidio e difícil de encontrar do que essa vontade do legislador. Primeiro porque inexiste o legislador como pessoa física. Há um corpo legislativo. E não é difícil imaginar que uma lei pode não significar a vontade sequer de um dos seus componentes, pois que, numa solução de compromisso, significa apenas uma vontade média. Segundo porque, regra geral, os anteprojetos e projetos de legislações codificadas são elaborados por técnicos (os juristas também são técnicos) estranhos ao corpo legislativo. Terceiro porque, em um sistema como o nosso, intervém a vontade do Poder Executivo - também não uma vontade pessoal - na sanção da lei.

A teoria histórico-objetivista ou atualista procura, pela interpretação, a vontade da lei (voluntas legis). A lei, depois de nascida, adquire vida própria e sua vonade supera até à vontade ficta do legislado. Veja-se o problema da adequação do código à mutação sociológica, com maiores permissividades morais. Fosse possível de ser encontrada, certamente a vontade do legislador seria considerar desonesta a uma mulher que usasse tanga nas praias. Tal não é, no entanto, a vontade da lei.

\section{FORMAS DE INTERPRETAÇÃO}

4. Pode-se dividir a interpretação em três compartimentos: órgão de onde provém, meio utilizado pelo intérprete e resultado alcançado.

4.1 Pela origem da interpretação pode-se identificar a autêntica, a judicial e a doutrinal.

4.1.a A interpretação autêntica, também chamada legislativa, é a feita através de lei. Sua validade é geral e obrigatória, operando ex tunc (isto é, a norma interpretadora retrotrai à data da norma interpretada). Pode ser contextual, quando no mesmo texto uma norma interpreta outra (v.g. conceito de funcionário público), ou posterior, quando outra lei é editada para interpretar a anterior.

A interpretação autêntica só deve ser utilizada em casos extremos, pois o seu abuso criaria um caos legislativo, paralisando o direito.

4. MANUEL DE ANDRADE, Ensaio sobre a Teoria da Interprefação das Leis, 1963, p. 15. EDUARDO CORREIA, Direito Criminal, 1963, v. I, p. 135. 
4.1.b A interpretação judicial provém dos juízos, coletivos e singulares, com a decisão do caso concreto através dos acórdãos e sentenças. Possui apenas valor particular, não obrigando nem mesmo o intérprete. Assim, se um juiz ou tribunal quizer interpretar a lei, no caso seguinte, de forma diferente à que fez anteriormente, pode fazê-lo. O conjunto de decisões uniformes e reiteradas forma a jurisprudência.

Essa inexistência de caráter normativo à decisão judicial sofre duas exceções. A primeira, na Justiça do Trabalho, quanto ao acórdão sobre dissídio coletivo. A segunda, com influência penal, na adoção, pelo Supremo Tribunal Federal, das chamadas súmulas da jurisprudência predominante, que só podem ser modificadas atendidos determinados requisitos previstos no seu regimento interno. As súmulas têm o efeito, até, de impedir prosseguimento de recursos.

4.1.c A interpretação doutrinal representa a posição dos tratadistas e doutores. E a comunes opinio doctorum. Não possui valor geral ou particular. As exposições de motivos dos códigos penais são interpretações doutrinais.

4.2 No exame dos meios utilizados pelo intérprete, encontra-se a interpretação gramatical (ou textual, literal, linguística) e a lógica ou teleológica.

4.2. a A interpretação gramatical é a mais simples. Visa apenas encontrar o sentido das palavras. Utiliza a sintaxe. Para KOHLER, ${ }^{5}$ elimina as demais, quando baste.

Essa afirmação, no entanto, não encontra valor no direito penal. Embora possa bastar a outro ramo jurídico a simples interpsetação gramatical (v.g. no direito administrativo, a ausência da sede para concessão de diárias), tal não ocorre no mundo jurídico-penal. Não serve para saber-se da existência de um homicídio o simples alcance do sentido das palavras matar alguém. Tcius matar Caius, por si só, do sentido das palavras matar alguém. Ticius matar Caius, por si só, de um tipo. Para se concluir pela existência do homicídio, necessita-se de mais: houve ação? há causa de exclusão da antijuridicidade? o agente é capaz de culpa? há dolo ou culpa? era exigível, de Ticius, um comportamento conforme o direito? Só a resposta afirmativa a todas essas perguntas dará a certeza da existência do crime. Isso demonstra a ineficácia da interpretação gramatical, salvo quanto à com. posição objetiva do tipo.

5. V. nota 4, MANUEL DE ANDRADE, p. 30.

6. V. nota 3, p. 107. 
4.2.b A interpretação lógica ou teleológica é, para $M A U R A C H,{ }^{6}$ a única válida no direito penal. $O$ que se deve buscar é a razão finalística da lei. E nisso tem importância saber-se exatamente qual seja o bem jurídico tutelado.

$\mathrm{Na}$ interpretação teleológica utilizam-se cinco elementos: o sistemático ou dogmático; o histórico; o direito comparado; o extrajurídico; e o sociológico.

4.2.b.1 A importância do elemento dogmático ou sistemático pode ser sentida no exemplo que se deu em 4.2.a. A análise de uma conduta não se restringe à sua adequação típica. Vai além: na indagação da antijuridicidade e culpabilidade. Porém, mesmo antes, para saber-se se houve ação, utiliza-se o elemento dogmático: no exame da vontade da ação, da sua exteriorização, do nexo de casualidade física.

4.2.b.2 O elemento histórico deve ser utilizado na análise do bem jurídico: necessidades e pressões que intervieram na elaboração da lei; visão histórica do instituto ou crime; evolução sofrida. Tome-se, por exemplo, o crime continuado. A razão moderna da sua menor punibilidade em relação ao concurso de crimes está no afrouxamento dos freios inibitórios, pela diminuição da censurabilidade pessoal. Mas para se entender a razão do instituto, embora a opinião contrária de CORREIA, ${ }^{7}$ deve-se remontar aos práticos ${ }^{8}$ ou aos glosadores e post-glosadores da Idade Média ${ }^{9}$ e deles alcançar 0 momento atual.

4.2.b.3 O direito comparado tem importância na medida em que determinado instituto ou crime foi inspirado em legislação alienígena. Note-se que o código penal de 1940 foi claramente calcado do código Rocco de 1930, em vigor até hoje na Itália. Os fatores políticos e sociais italianos assemelhavam-se aos nacionais, na dédaca de 30 . Válido, portanto, buscar a opinião e o entendimento dos intérpretes italianos quanto a institutos ou delitos de acintosa semelhança.

Um exemplo de interpretação utilizando-se o direito comparado, embora terrivelmente errônea, nos dá mestre HUNGRIA quanto ao crime de denunciação caluniosa (art. 339). $O$ código alemão o capitula no § 164. E faz, no n. ${ }^{\circ} 6$, uma exigência, quando seja interposta ação sobre o fato denunciado: a suspensão de todo procedimento ou decisão concernente à denunciação caluniosa. $O$ código penal

7. EDUARDO CORREIA, A Teoria de Concurso em Direito Criminal, 1963, p. 1965.

8. ANIBAL BRUNO, Direito Penal, t. 2., p. 295. MANOEL PEDRO PIMENTEL, Do Crime Continuado, p. 39.

9. JOSÉ FREDERICO MARQUES, Trałado de Direito Penal, v. 2, p. 335. 
brasileiro não tem a exigência. Assim, o Ministério Público, dominus litis, pode denunciar nos mesmos autos de inquérito policial, pelo princípio da obrigatoriedade da ação penal pública, ao autor da denunciação caluniosa, sem a necessidade do precedente arquivamento quanto à vítima da denunciação. HUNGRIA, porém, entendeu exigível essa regra no direito positivo nacional - embora dele não conste -, certamente movido por seu conhecido entusiasmo pela legislação germânica. E embora quebrando o sistema do código penal - de exigir o que dele não conste -, bem como ofendendo o princípio da titularidade da lide pelo Ministério Público, subordinado como fica à classificação do crime dada pela autoridade policial, a jurisprudência nacional, exceção feita à paulista, tem exigido, por mero desamor à pesquisa, o precedente arquivamento.

4.2.b.4 Os tipos, modernamente, não são elaborados apenas com elementos objetivos e descritivos. A ciência jurídica se socorre das demais. $O$ infanticídio não é só a mãe matar o filho durante o parto ou logo após. Mistér que atue, segundo o código penal de 1940, sob a influência do estado puerperal. 'E o que seja estado puerperal, suas consequências e duração, não será respondido pelo direito penal, mas por uma ciência extra-jurídica. Da mesma forma, o conceito de mulher honesta, necessário para compor, por exemplo, o tipo de posse sexual mediante fraude previsto no artigo 216 do código penal ainda vigente, é extra-jurídico.

4.2.b.5 Finalmente, o elemento sociológico. Já se disse que a lei nasce muito tempo após se fazer necessária. Assim, se se fosse adotar um conceito imutável, verbi gratia, de ato obsceno, o direito penal estaria se transformando num óbice à evolução sociológica. Mestre HUNGRIA fixou um critério, ao examinar o crime de sedução, que me parece utilíssimo no posicionamento desse elemento: "a conduta deve ser apreciada em relação ao meio social em que vive. Assim, a donzela que se exiba seminua nas praias de banho de Copacabana não é uma impudica, do mesmo modo que não o é a rapariga de condição inferior que, por exemplo, frequenta as chamadas "gafieiras" (clubes de dança do troisième dessous), pois que, num e noutro caso, não ofendem a moral do grupo social a que pertencem". ${ }^{10}$

4.3 O resultado alcançado pelo intérprete pode ser declarativo, restritivo e extensivo.

4.3.a E declarativo quando esclarece a dubiedade ou ambiguidade do texto. Por exemplo, o conceito de funcionário público, de mulher honesta, de adultério (apenas a conjunção carnal normal).

10. Comentários ao Código Penal, v. VIII, p. 161. 
4.3.b Restritiva é a interpretação que se dá ao conceito de doença mental, por exemplo, para impedir que abrigue casos de embriaguez não patológica ou estados de emoção e paixão de origem não mórbida.

4.3.c Extensiva é a interpretação que alarga o alcance do texto. Tem-se exemplo no crime continuado (art. 51, § 2..$^{\circ}$. O código penal, adotando a teoria objetiva pura, determina os elementos que devem oexistir para que se considere a repetição de crimes como uma continuação. Mas a citação não é exaustiva, tanto que o texto fala em outros semelhantes, propiciando a extensão. $O$ mesmo ocorre nas qualificativas do homicídio, quando $\circ \mathrm{n} .{ }^{\circ} \mathrm{III}, \S 2 .^{\circ}$, do art. 121, fala em outro meio insidioso ou cruel.

O problema da interpretação extensiva desagua na analogia. Verdade que a interpretação analógica é diferente da analogia. CORREIA repudia a interpretação analógica, à qual reconhece valor apenas no domínio do elemento histórico. ${ }^{11}$

Mas não há negar que o direito permite, expressamente, a possibilidade de interpretação analógica.

\section{ANALOGIA}

5. A analogia já não tem uma relação tranquila com o direito penal. As lacunas que, no direito positivo, são inevitáveis, levando BRUNO a afirmar que o legislador penal não pode querer possuir a capacidade de esgotar todas as hipóteses, que se não reconhece aos demais, ${ }^{12}$ no direito penal, quanto à parte especial, são intencionais. E o artigo $4 .^{\circ}$ da Lei de Introdução ao Código Civil determina ao juiz que se socorra da analogia, quer seja a legis (identidade com alguma lei), quer seja a juris (suprimento da lacuna pelos princípios gerais do direito), mas não se exima de ditar a sentença.

No âmbito jurídico-penal brande-se com o princípio da reserva legal como impeditivo da analogia integradora de tipos, o que não me parece correto. $O$ princípio da legalidade não surgiu para impedir a analogia, mas sim a aplicação da lei a fatos pretéritos. ${ }^{13}$ WELZEL afirma que se satisfaz ao nullum crimen sine lege substituindo-se a parte especial por um conceito material de crime. ${ }^{14} \mathrm{E}$ com isso se não está impedindo a analogia. Veja-se, por exemplo, a Novela de 1935, da Alemanha nacional-socialista, que admitiu a cria-

11. V. nota 4, EDUARDO CORREIA, p. 145.

12. V. nota 8, ANIBAL BRUNO, t. 1, p. 208.

13. V. nota 3, p. 112

14. Derecho Penal Alemán, 11.a ed., 1970, p. 74. 
ção de tipos quando a ação ofendesse ao são sentimento do povo alemão: a reserva legal estava atendida, mas havia permissão à analogia.

O que, em verdade, impede a analogia integradora no direito penal é o princípio da tipicidade. Tanto assim que a doutrina é unânime em considerar proibida a analogia quanto à parte especial: criação de tipos e exasperação de penas. Vale dizer, o que está ve. dado é o uso da analogia em prejuízo, in malam partem. Mas não se impede a analogia a favor, a analogia em bonam partem. Porque com relação à parte geral dos códigos não vige o princípio da tipicidade, porém tão só o da legalidade. Assim é que se admite a criação analógica de causas excludentes da antijuridicidade e da culpabilidade, em que pese a abalisada oposição de HUNGRIA, fundado no caráter excepcional das normas penais e excepcionalíssimc das decriminantes e exculpantes.

Nada obsta, no entanto, que se admita a existência do aborto sentimental impunível não só na gravidez resultante de estupro, mas também na resultante de atentado violento ao pudor.

\section{CONFLITO APARENTE}

6. Problema relacionado com a interpretação da lei penal é o chamado concurso ou conflito aparente de normas penais. $O$ direito é um todo harmônico e unitário que inadmite antagonismos e contradições. O conflito de normas é diferente do concurso de crimes, real ou ideal. Neste, deve-se saber quantas normas ou quantas vezes foram ofendidas por uma só ou várias ações. Naquele, qual a norma que deve ser subsumida a determinada ação.

E, pois, tarefa de interpretação, saber-se se a conduta realizou tal ou qual tipo. Para a solução desse conflito aparente, inúmeros princípios são apontados, merecendo a preferência dos autores o da especialidade, $\circ$ da consunção, $\circ$ da subsidiariedade e $\circ$ da alternatividade.

6.1 Diz-se que há especialidade quando entre duas ou mais normas existe relação de gênero a espécie. A norma especial derroga a norma geral. A norma especial é a norma geral mais alguns requisitos. É especial o infanticídio em relação ao homicídio; o roubo, em relação ao furto, a denunciação caluniosa, em relação à colúnia. Todo crime complexo, em sentido amplo ou estrito, é especial em relação aos seus componentes. Na especialidade, a norma geral está compreendida, está dentro, da especial. Esta, porém, é mais completa. 
6.2 A consunção ocorre quando os crimes são etapas necessárias e imprescindíveis para o resultado mais grave e o bem jurídico de um compreende, abrange, o dos demais. A norma consumente derroga a norma consumida. Lesões corporais são consumidas pelo homicídio; violação de domicílio, pelo furto na casa.

6.3 Na subsidiariedade a lei subsidiária é derrogada pela lei primária. A subsidiariedade pode ser prevista na lei (art. 132 do có. digo penal de 1940) ou pode não ser: furto qualificado pelo arrom. bamento e o dano.

6.4 A alternatividade ocorre no chamado crime de conteúdo variável, de que é exemplo o tráfico de entorpecentes (art. 281). O agente pode praticar uma ou várias ações (importar, exportar, ter em depósito, etc.): o crime é um só.

\section{VII "IN DUBIO PRO REO"}

7. Resta dizer que o brocardo in dubio pro reo diz respeito oo direito processual, não ao material. O direito nunca é duvidoso. A prova é que pode não oferecer uma conclusão, máxime se atentarse a que o processo penal busca a verdade material.

Desassiste razão a CORREIA, quando afirma que se deve aplicar - princípio quando a interpretação seja incapaz de conduzir a um resultado. ${ }^{15}$

15. V. nota 11, p. 150. 